\title{
Protective Effects of 4-Phenylbutyrate Derivatives on the Neuronal Cell Death and Endoplasmic Reticulum Stress
}

\author{
Seisuke Mimori, ${ }^{a}$ Yasunobu Okuma, ${ }^{b}$ Masayuki Kaneko, ${ }^{b}$ Koichi Kawada, ${ }^{b}$ Toru Hosoi, ${ }^{c}$ \\ Koichiro Ozawa, ${ }^{c}$ Yasuyuki Nomura, ${ }^{d}$ and Hiroshi Hamana*,a \\ ${ }^{a}$ Department of Pharmaceutical Chemistry, Chiba Institute of Science; ${ }^{b}$ Department of Pharmacology, Faculty of \\ Pharmaceutical Sciences, Chiba Institute of Science; Choshi, Chiba 288-0025, Japan: ${ }^{\circ}$ Department of Pharmacother- \\ apy, Graduate School of Biomedical Sciences, Hiroshima University; 1-2-3 Kasumi, Minami-ku, Hiroshima 734-8553, \\ Japan: and ${ }^{d}$ Laboratory of Pharmacotherapeutics, Yokohama College of Pharmacy; Yokohama, Kanagawa 245-0066, \\ Japan. Received August 12, 2011; accepted November 1, 2011; published online November 7, 2011
}

Endoplasmic reticulum (ER) stress responses play an important role in neurodegenerative diseases. Sodium 4-phenylbutyrate (4-PBA) is a terminal aromatic substituted fatty acid that has been used for the treatment of urea cycle disorders. 4-PBA possesses in vitro chemical chaperone activity and reduces the accumulation of Parkin-associated endothelin receptor-like receptor (Pael-R), which is involved in autosomal recessive juvenile parkinsonism (AR-JP). In this study, we show that terminal aromatic substituted fatty acids, including 3-phenylpropionate (3-PPA), 4-PBA, 5-phenylvaleric acid, and 6-phenylhexanoic acid, prevented the aggregation of lactalbumin and bovine serum albumin. Aggregation inhibition increased relative to the number of carbons in the fatty acids. Moreover, these compounds protected cells against ER stress-induced neuronal cell death. The cytoprotective effect correlated with the in vitro chemical chaperone activity. Similarly, cell viability decreased on treatment with tunicamycin, an ER stress inducer, and was dependent on the number of carbons in the fatty acids. Moreover, the expression of glucose-regulated proteins 94 and 78 (GRP94, 78) decreased according to the number of carbons in the fatty acids. Furthermore, we investigated the effects of these compounds on the accumulation of Pael-R in neuroblastoma cells. 3-PPA and 4-PBA significantly suppressed neuronal cell death caused by ER stress induced by the overexpression of Pael-R. Overexpressed Pael-R accumulated in the ER of cells. With 3-PPA and 4-PBA treatment, the localization of the overexpressed Pael-R shifted away from the ER to the cytoplasmic membrane. These results suggest that terminal aromatic substituted fatty acids are potential candidates for the treatment of neurodegenerative diseases.

Key words 4-phenylbutyrate; 3-phenylpropionate; endoplasmic reticulum stress

Recent studies have shown that small molecular weight compounds help to prevent aggregation of amyloid- $\beta$ proteins, ${ }^{1,2)}$ prion proteins, ${ }^{3)}$ and polyglutamine proteins. ${ }^{4)}$ Neurodegenerative diseases are typically caused by unfolded protein accumulation. Thus, a variety of pharmacological approaches have been undertaken in order to prevent protein aggregation.

Molecular chaperones, such as heat shock proteins (Hsps), provide cellular protection by protecting nascent proteins from misfolding and reducing protein-protein aggregate formations. Hsp70 reduces the in vivo and in vitro amounts of misfolded and aggregated $\alpha$-synuclein ( $\alpha$-syn), which is the major component of Lewy bodies in Parkinson's disease (PD), and protects neuronal cells from $\alpha$-syn-dependent neurotoxicity. ${ }^{5}$

Chemical chaperones are low molecular weight compounds that mimic the functions of intracellular molecular chaperones. We are interested in chemical chaperones as potential candidates as therapeutic agents, especially for neurodegenerative diseases. Mutations in the gene of Parkin, an ubiquitin ligase, have been linked to autosomal recessive juvenile parkinsonism (AR-JP) ${ }^{6}{ }^{6}$ Mutations of Parkin reduce the activity of the ubiquitin-proteasome degradation pathway and presumably cause an accumulation of its substrates, such as Parkin-associated endothelin receptor-like receptor (Pael$\mathrm{R})$, which is expressed in dopaminergic neurons of the zona compacta of the substantia nigra in the AR-JP brain. ${ }^{7-9)}$ The mutant Parkin-induced accumulation of Pael-R causes endoplasmic reticulum (ER) stress, and this mechanism has been proposed to be responsible for neuronal cell death in AR-JP. ${ }^{8,9}$ We have previously reported that 4-phenylbutyrate (4-PBA) possesses in vitro chemical chaperone activity, which prevents the aggregation of denatured $\alpha$-lactalbumin $(\alpha-\mathrm{LA})$ and bovine serum albumin (BSA) ${ }^{10)}$ Furthermore, we investigated the effects of 4-PBA on the accumulation of Pael-R. 4-PBA restored the normal levels of expression of Pael-R protein and suppressed ER stress induced by the overexpression of Pael-R. ${ }^{10)}$ In addition, we have previously reported that 4-PBA protected against ischemic injury and ER stress-induced neuronal cell death. ${ }^{11}$ 4-PBA is an orally bioavailable terminal aromatic substituted fatty acid that is used in the treatment of various diseases, such as urea metabolism disorders, ${ }^{12)}$ homozygous $\beta$-thalassemia, ${ }^{13)}$ and spinal muscular atrophy, ${ }^{14)}$ and for the treatment of tumors. ${ }^{15)}$ Additionally, 4-PBA is remarkable to novel therapeutic agents of type 2 diabetes $^{16)}$ and familial hypercholesterolemia. ${ }^{17)}$ Furthermore, 4-PBA exerts significant neuroprotective effects in some mouse models of human $\mathrm{PD}^{18,19)}$ and Alzheimer's disease. ${ }^{20)}$ Moreover, 4-PBA possesses histone deacetylase (HDAC)-inhibitor activity, and it is able to penetrate the blood-brain barrier. ${ }^{18-20)}$

In this study, in order to investigate the structure-activity relationships of 4-PBA analogs, we examined the effect of terminal aromatic substituted fatty acids, which act as chemical chaperones, on protein aggregation and ER stress-induced cell death.

\section{MATERIALS AND METHODS}

Materials and Reagents Tunicamycin (Tm) was obtained from Wako Pure Chemical Industries, Ltd. (Osaka, Japan). 
3-Phenylpropionic acid (3-PPA), 4-PBA, 5-phenylvaleric acid (5-PVA), and 6-phenylhexanoic acid (6-PHA) were purchased from Wako Pure Chemical Industries, Ltd. (Osaka, Japan).

Cell Culture Human neuroblastoma SH-SY5Y cells were maintained in Dulbecco's modified Eagle's medium (SigmaAldrich Co., St. Louis, MO, U.S.A.) with 10\% heat-inactivated fetal calf serum. Cell lines were routinely cultured at $37^{\circ} \mathrm{C}$ in humidified $5 \% \mathrm{CO}_{2} / 95 \%$ air.

Induction of $\alpha$-Lactalbumin Aggregation and Measurement of Chaperone Activity $\alpha$-LA from bovine milk was purchased from Sigma-Aldrich Co. Holo- $\alpha$-LA was obtained by dissolving the protein in phosphate buffer containing $0.1 \mathrm{~mm} \mathrm{CaCl} 2 .{ }^{21}$ The phosphate buffer consisted of $14 \mathrm{~mm}$ $\mathrm{KH}_{2} \mathrm{PO}_{4}, 86 \mathrm{~mm} \mathrm{~K} \mathrm{HPO}_{4}$, and $150 \mathrm{~mm} \mathrm{KCl} \mathrm{(pH} \mathrm{7.5).} \mathrm{Apo-} \alpha-$ LA was obtained by dissolving the protein in phosphate buffer containing $2.5 \mathrm{~mm}$ ethylenediaminetetraacetic acid (EDTA). Reduced $\alpha$-LA (r-LA) was prepared by incubating the protein in phosphate buffer containing $2.5 \mathrm{~mm}$ EDTA and $5 \mathrm{~mm}$ dithiothreitol for $30 \mathrm{~min}$ at $25^{\circ} \mathrm{C}^{22)} \mathrm{BSA}$ was denatured with $7.2 \mathrm{M}$ guanidine hydrochloride at $25^{\circ} \mathrm{C}$ overnight in $210 \mu \mathrm{M}$ phosphate buffer ( $\mathrm{pH} 7.5){ }^{23)}$ Aggregates of denatured BSA were formed by a 50 -fold rapid dilution in phosphate buffer at $25^{\circ} \mathrm{C}$ and incubation for $3.5 \mathrm{~h}$. For the induction of r-LA aggregation, $r-L A$ was mixed with BSA aggregates in phosphate buffer, and the mixture containing $14 \mu \mathrm{M}$ of r-LA and $2.6 \mu \mathrm{M}$ of BSA was incubated at $37^{\circ} \mathrm{C}$. The aggregation of r-LA induced by BSA aggregates was monitored in the presence or absence of different terminal aromatic substituted fatty acids $[0.3,1$, or $3 \mathrm{~mm}$ of 3-PPA, 5-PVA, and 6-PHA or $3 \mathrm{~mm} 4$-PBA]. Aggregation was monitored by measuring turbidity at $488 \mathrm{~nm}$ using a spectrophotometer (Hitachi Research Laboratory, Hitachi, Ltd., Ibaraki, Japan).

Cell Death Assay Subconfluent SH-SY5Y cells grown in 6-well plates were treated with $\mathrm{Tm}$ in the presence of the test compounds for $48 \mathrm{~h}$. In order to measure the remaining viable adherent cells, the culture medium was removed and then stained with $0.1 \%$ crystal violet (Wako Pure Chemical Industries, Ltd.) for $20 \mathrm{~min}$ at $20^{\circ} \mathrm{C}$. After removal of the dye, the medium was washed with $1 \mathrm{~mL}$ of PBS 2 times and then allowed to dry. Stained cells were lysed with $500 \mu \mathrm{L}$ of $0.5 \%$ sodium dodecyl sulfate by incubation with agitation for $20 \mathrm{~min}$ at $20^{\circ} \mathrm{C}$. The absorbance of the extracts was measured at $590 \mathrm{~nm}$. The percent viability compared to untreated controls was calculated by using the following equation: $\left(\mathrm{OD}_{\text {treated }}+\mathrm{OD}_{\text {background }}\right) /\left(\mathrm{OD}_{\text {treated }}-\mathrm{OD}_{\text {background }}\right) \times 100=\%$ viability.

Immunoblotting Cells were lysed in $20 \mathrm{~mm} \mathrm{~N}$-(2hydroxyethyl)piperazine- $N$ '-2-ethanesulfonic acid (HEPES)$\mathrm{NaOH}$ (pH 7.4), $150 \mathrm{~mm} \mathrm{NaCl}, 5 \mathrm{~mm}$ EDTA, 1\% Nonidet P-40, $1 \mathrm{~mm}$ phenylmethylsulfonyl fluoride, $10 \mu \mathrm{g} / \mathrm{mL}$ aprotinin, and $10 \mu \mathrm{g} / \mathrm{mL}$ leupeptin. The following were used as primary antibodies: KDEL (Enzo Life Sciences, Inc., Farmingdale, NY, U.S.A.) (diluted 1:1,000), glyceraldehyde-3-phosphate dehydrogenase (GAPDH; Santa Cruz Biochemistry, Santa Cruz, CA, U.S.A.), acetyl-histone H3 (Lys9) antibody (Cell Signaling Technology, Inc., Beverly, MA, U.S.A.), and FLAG (M2) (Sigma-Aldrich Co.) (diluted 1:2000). Horseradish peroxidase-conjugated anti-mouse immunoglobulin $\mathrm{G}$ (IgG) (GE Healthcare Bio-Sciences Corp., Piscataway, NJ, U.S.A.) (diluted $1: 2000)$ and anti-rabbit IgG (GE Healthcare Bio-Sciences Corp.) or anti-goat IgG (Cell Signaling Technology, Inc.) (di- luted $1: 2000)$ antibodies were used as secondary antibodies. Bands were detected using the enhanced chemiluminescence system (GE Healthcare Bio-Sciences Corp.).

Immunocytochemistry SH-SY5Y cells that were stably transfected with human Pael-R expression vectors were fixed with cold methanol at $-20^{\circ} \mathrm{C}$ for $20 \mathrm{~min}$. The cells were then stained with anti-FLAG (M2, 1:200) and anti-cleaved caspase-3 (1:200; Cell Signaling Technology, Inc.). Anti-mouse antibody that was conjugated to Alexa 488 and anti-rabbit antibody that was conjugated to Alexa 546 (1:200; Invitrogen Corporation, Burlingame, CA, U.S.A.) were used as second antibodies. Fluorescent images were acquired using a Zeiss LSM 510 Meta confocal microscope (Carl Zeiss MicroImaging Oberkochen, GmbH, Germany).

Statistical Analyses Results are expressed as means \pm S.E. Statistical analyses were performed using the JonckheereTerpstra and Dunnett's tests.

\section{RESULTS}

Terminal Aromatic Substituted Fatty Acids Act as Chemical Chaperones in Vitro 4-PBA acts as a chemical chaperone..$^{10-20)}$ In order to elucidate whether terminal aromatic substituted fatty acids possess chaperone activity, we examined the effects of the test compounds on the in vitro aggregation of $\alpha$-LA with BSA. Holo- $\alpha$-LA is a 4 -disulfide bond calcium-binding protein. r-LA, which is formed by calcium depletion and dithiothreitol treatment, exists in an even more relaxed and expanded structure, and it is a target recognized and bound by molecular chaperones. r-LA is soluble in neutral and reduced buffer at $25^{\circ} \mathrm{C}$ but forms aggregates in the presence of other denatured proteins. ${ }^{21-23)}$ The aggregation of r-LA, which was induced by the addition of denatured BSA that was produced by guanidine hydrochloride and incubated at $37^{\circ} \mathrm{C}$, was detected as increased turbidity. A time-dependent increase in turbidity was suppressed by the addition of terminal aromatic substituted fatty acids in a dose-dependent manner, indicating that these compounds inhibited the aggregation of r-LA and BSA (Fig. 1).

The chemical chaperone activity of different concentrations of each terminal aromatic substituted fatty acid was compared with $3 \mathrm{~mm}$ 4-PBA (Figs. 1A-C). The inhibitory effects of each terminal aromatic substituted fatty acid on aggregation were compared at a concentration of $3 \mathrm{~mm}$. There was a tendency for the aggregation inhibition of these compounds to increase according to the number of carbons in the terminal aromatic substituted fatty acids (Fig. 1D).

Effect of Terminal Aromatic Substituted Fatty Acids on Neuronal Cell Death Next, we investigated the effect of terminal aromatic substituted fatty acids on neuronal cell death induced by the ER. We used Tm, an inhibitor of protein $\mathrm{N}$ glycosylation and an ER stress inducer. ${ }^{24,25)}$ Cells were treated with $0.1 \mu \mathrm{g} / \mathrm{mL}$ of $\mathrm{Tm}$ in the presence of terminal aromatic substituted fatty acids for $48 \mathrm{~h}$. We examined the effects of the test compounds on cell viability in SH-SY5Y cells under ER stress using a crystal violet assay (Fig. 2). There was a tendency for the protective effects on neuronal cell death to increase according to the number of carbons in the terminal aromatic substituted fatty acids. Interestingly, these results correlated well with the potency of the preventive action of these compounds on protein aggregation. 

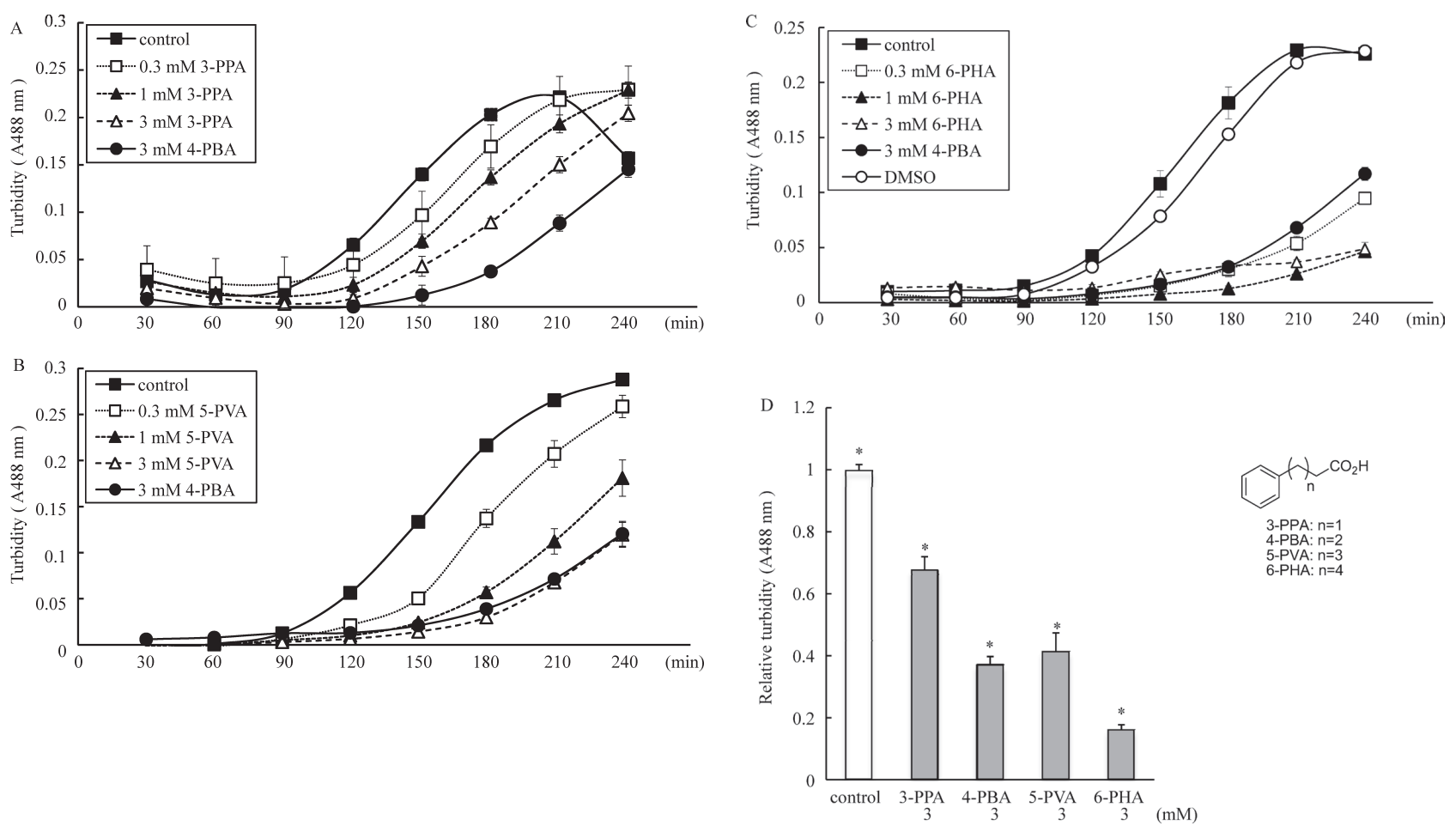

Fig. 1. Inhibitory Effects of Terminal Aromatic Substituted Fatty Acids on the Protein Aggregation of $\alpha$-Lactalbumin in Vitro (A-C)

Reduced $\alpha$-lactalbumin (r-LA) was prepared by treating $\alpha$-LA with $2.5 \mathrm{~mm}$ ethylenediaminetetraacetic acid and $5 \mathrm{~mm}$ dithiothreitol for $30 \mathrm{~min}$ at $25^{\circ} \mathrm{C}$. Bovine serum albumin (BSA) was denatured with $7.2 \mathrm{M}$ guanidine hydrochloride and diluted 50 -fold to form aggregates. Aggregation of r-LA was induced by the addition of denatured BSA at $37^{\circ} \mathrm{C}$. Aggregation increases were monitored by measuring the optical density at $488 \mathrm{~nm}$. Aggregation was indicated by turbidity in the presence or absence of the indicated additives [0.3, 1, or $3 \mathrm{~mm}$ of 3-phenylpropionate (3-PPA), 5-phenylvaleric acid (5-PVA), and 6-phenylhexanoic acid (6-PHA) or 3 mM 4-PBA] for the periods indicated. The values are the means \pm S.E. of four independent experiments. (D) Due to slight difference of experimental condition, maximum turbidity and time to reach peak are changed in these experiments. Relative turbidities are expressed as the ratios of the turbidities of terminal aromatic substituted fatty acids to the corresponding controls. The peak points of each control experiment were $210 \mathrm{~min}$ (Fig. 1A), $240 \mathrm{~min}$ (Fig. 1B) and $210 \mathrm{~min}$ (Fig. 1C), respectively. The values are the means \pm S.E. of four independent experiments $\left({ }^{*} p=0.0005\right.$ : compared with control, Jonckheere-Terpstra test).

Effects of Terminal Aromatic Substituted Fatty Acids on the ER Stress-Induced Expression of ER Chaperones ER stress triggers cellular unfolded protein responses, which result in an increase in the expression of unfolded protein response-regulated genes, such as GRP78 and GRP94, which are ER-resident chaperones. We investigated whether the levels of expression of GRP94 and GRP78 that were induced by treatment with Tm were suppressed by the terminal aromatic substituted fatty acids (Fig. 3A). Although the relative density of GRP94/GAPDH increased in SH-SY5Y cells on treatment with Tm, we observed that the relative density of GRP94/ GAPDH was increased with 3-PPA treatment compared to that of vehicle (Fig. 3B). Treatment with 5-PVA and 6-PHA significantly suppressed the relative density of GRP94/GAPDH, indicating that these compounds reduced ER stress. Similarly, although the relative density of GRP78/GAPDH was decreased on treatment with only 5-PVA and 6-PHA, we observed that the relative density of GRP78/GAPDH in cells treated with 3-PPA and 4-PBA was not decreased but actually higher than that of the vehicle control. These results correlated well with the potency of these compounds in protecting against ER stress-induced neuronal cell death and their preventive actions on protein aggregation

Effects of Terminal Aromatic Substituted Fatty Acids against Neuronal Cell Death Induced by Overexpression of Pael-R Almost all neurodegenerative disorders are characterized by the accumulation of misfolded and aggregated proteins in a variety of intracellular or extracellular regions,

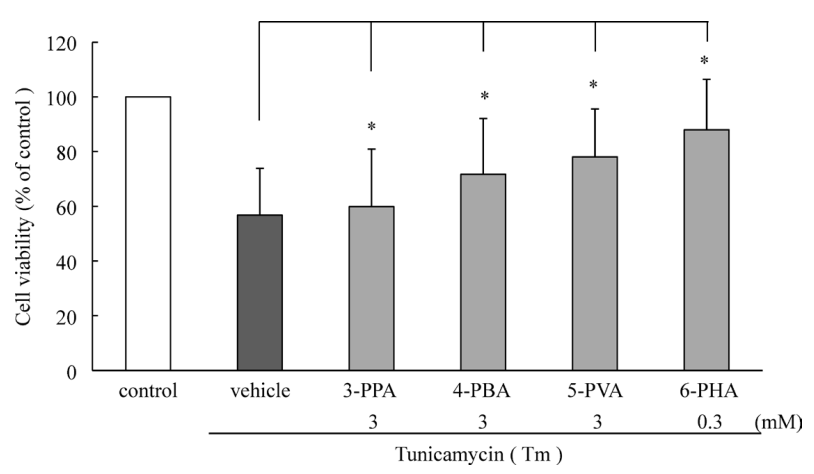

Fig. 2. Protective Effects of Terminal Aromatic Substituted Fatty Acids against ER Stress-Induced Cell Death in Human Neuroblastoma SHSY5Y Cells

SH-SY5Y cells were treated with $0.1 \mu \mathrm{g} / \mathrm{mL}$ tunicamycin $\left(T_{\mathrm{m}}\right)$ in the presence or absence of test compounds for $48 \mathrm{~h}$. Cell viability was determined using a crystal violet assay, and the results are expressed as the means \pm S.E. (22 independent experiments in duplicate) $(* p<0.05$ : compared with vehicle control, Dunnett's test).

including the ER. The pathophysiological mechanisms of AR-JP, which is one such disorder, are possibly linked to ER stress. ${ }^{8,9)}$ We investigated whether terminal aromatic substituted fatty acids, as well as 4-PBA, possess protective effects on neuronal cell death induced by an overexpression of Pael-R. We examined the effects of terminal aromatic substituted fatty acids on cell viability in SH-SY5Y cells under ER stress induced by the overexpression of Pael-R using the crystal violet 

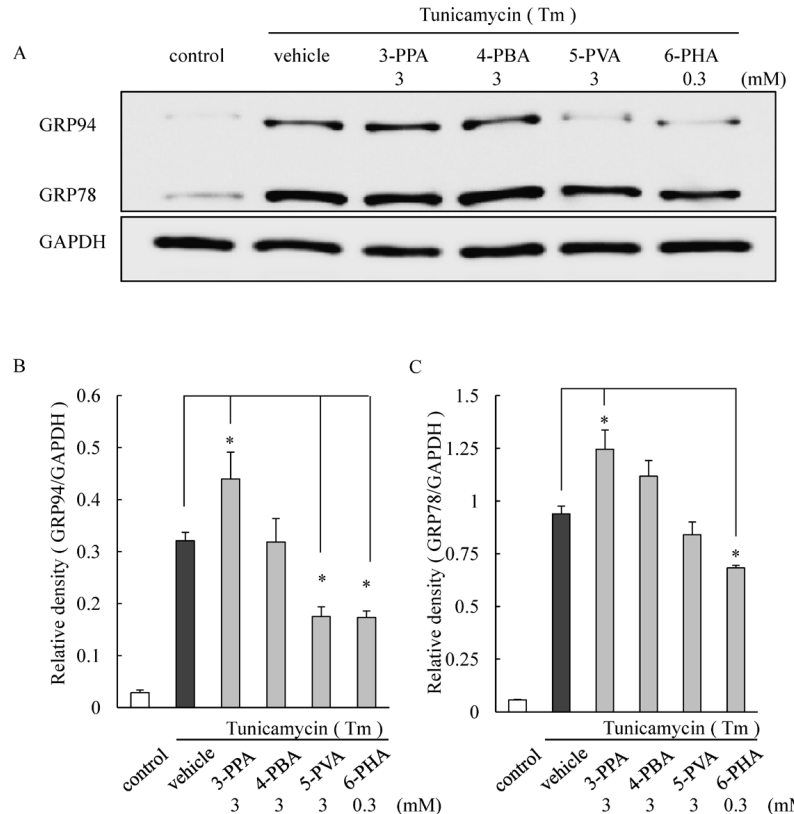

Fig. 3. Effects of Terminal Aromatic Substituted Fatty Acids on the Levels of Expression of ER Stress-Induced GRP94 and GRP78 in Human Neuroblastoma SH-SY5Y Cells

(A) Effect of the test compounds on the expression of GRP94 and GRP78 induced by ER stress. SH-SY5Y cells were treated with $100 \mathrm{ng} / \mathrm{mL} \mathrm{Tm}$ in the presence or absence of test compounds, and immunoblotting was performed using an anti-KDEL antibody. GAPDH served as internal control in the immunoblotting analysis. The data presented are from a representative experiment of five independent experiments performed. (B,C) The levels of GRP78 and GRP94 were quantified by densitometric analysis and normalized to that of the corresponding GAPDH internal control ( ${ }^{*} p<0.05$ : compared with vehicle control, Dunnett's test).

assay. Pael-R-induced cell death was suppressed by 3-PPA and 4-PBA (Fig. 4). In contrast, treatment with 5-PVA and 6-PHA did not suppress this Pael-R-induced cell death.

Effects of Terminal Aromatic Substituted Fatty Acids on the Intracellular Localization of Overexpressed Pael$\mathbf{R}$ We found a tendency for the inhibitory potency of these compounds to increase on aggregation according to the number of carbons in the terminal aromatic substituted fatty acids. This tendency was not consistent with the potency of these compounds to protect against Pael-R-induced cell death. These data suggest that other mechanisms exist to protect against Pael-R-induced cell death. To elucidate this possibility, the effects of terminal aromatic substituted fatty acids on Pael-R intracellular localization were assessed by immunocytochemical analyses. Overexpressed Pael-R was mainly localized in the ER and perinuclear sites. The accumulation of Pael- $R$ in the ER was prevented by treatment with 3-PPA and 4-PBA, which resulted in the partial restoration of the Pael-R localization in the ER to the plasma membrane (Fig. 5).

Effects of Terminal Aromatic Substituted Fatty Acids on Acetylated Histone $\mathrm{H3}$ Expression in Cells under ER Stress 4-PBA is not only a chemical chaperone but also as a histone deacetylase inhibitor. 4-PBA has been shown to facilitate the folding of several mutant proteins, including $\Delta$ F508-cystic fibrosis transmembrane conductance regulator (CFTR). ${ }^{26)}$ Although 4-PBA has been shown to inhibit the aggregation of several misfolded proteins, its properties as a histone deacetylase inhibitor have left its chaperone-like properties rather controversial. As a histone deacetylase inhibitor,

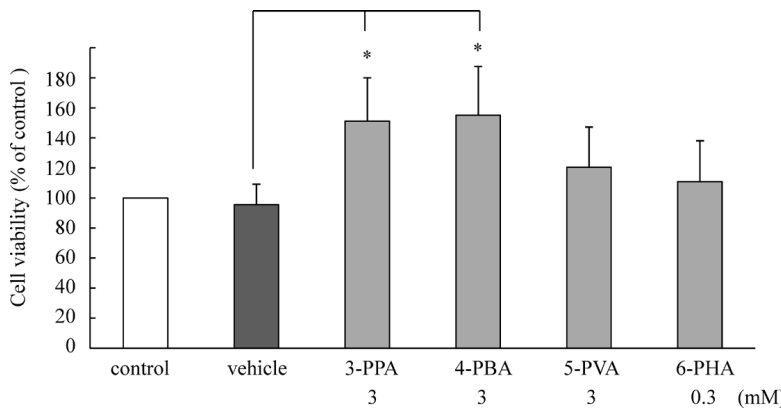

Fig. 4. Protective Effects of Terminal Aromatic Substituted Fatty Acids against Pael-R-Induced Cell Death in Human Neuroblastoma SH-SY5Y Cells

SH-SY5Y cells stably expressing Pael-R-FLAG were incubated in the presence or absence of terminal aromatic substituted fatty acids for $48 \mathrm{~h}$. About $10 \%$ cells overexpressed Pael-R underwent cell death. The cell viability was determined using the crystal violet assay, and the results were expressed as the means \pm S.E. (nine independent experiments in duplicate) $\left({ }^{*} p<0.05\right.$ : compared with vehicle control, Dunnett's test).

4-PBA has the ability to facilitate the transcription of a variety of genes, including those encoding hsps that are known to be involved in protein folding. ${ }^{27)}$ To investigate whether the several protective effects of terminal aromatic substituted fatty acids could be explained by their ability to inhibit histone deacetylation, we analyzed the levels of acetylated histone $\mathrm{H} 3$ in human neuroblastoma SH-SY5Y cells (Fig. 6). The level of acetylated histone $\mathrm{H} 3$ was not changed by Tm. Among the terminal aromatic substituted fatty acids tested, 4-PBA and 3-PPA significantly increased the level of acetylated histone H3. These results suggest that a relationship between histone deacetylase and chaperone interaction is related to the number of carbons in the regulating terminal aromatic substituted fatty acids.

\section{DISCUSSION}

In this study, we showed that terminal aromatic substituted fatty acids possessed chaperone activity in vitro. This effect exhibited a concentration-dependent pattern. Although the effective concentration of compounds used in this study may appear to be high, especially for 4-PBA, it is not so for 6-PHA because the physical properties of 6-PHA, which is an oil at room temperature, were different from those of other compounds. Therefore, we assume that a low concentration of 6-PHA $(0.3 \mathrm{~mm})$ is probably sufficient prevent aggregation between hydrophobic regions of unfolded proteins through physicochemical effects.

We previously reported that 4-PBA exhibits protective effects against ER stress-induced cell death. ${ }^{10)}$ The other terminal aromatic substituted fatty acids tested in this study are believed to exhibit similar mechanisms of action as for 4-PBA. In fact, the compounds possessed chemical chaperone activity (Fig. 1), reduced ER stress-induced cell death in the presence of Tm (Fig. 2), and suppressed the induction of GRP94 and GRP78 (Fig. 3). We found that 6-PHA was the most effective compound in suppressing the ER stress-induced cell death in the presence of Tm (Fig. 2). The protective effects of these compounds against ER stress-induced neuronal cell death tended to increase in relative to the number of carbons in the terminal aromatic substituted fatty acids. Moreover, this ten- 


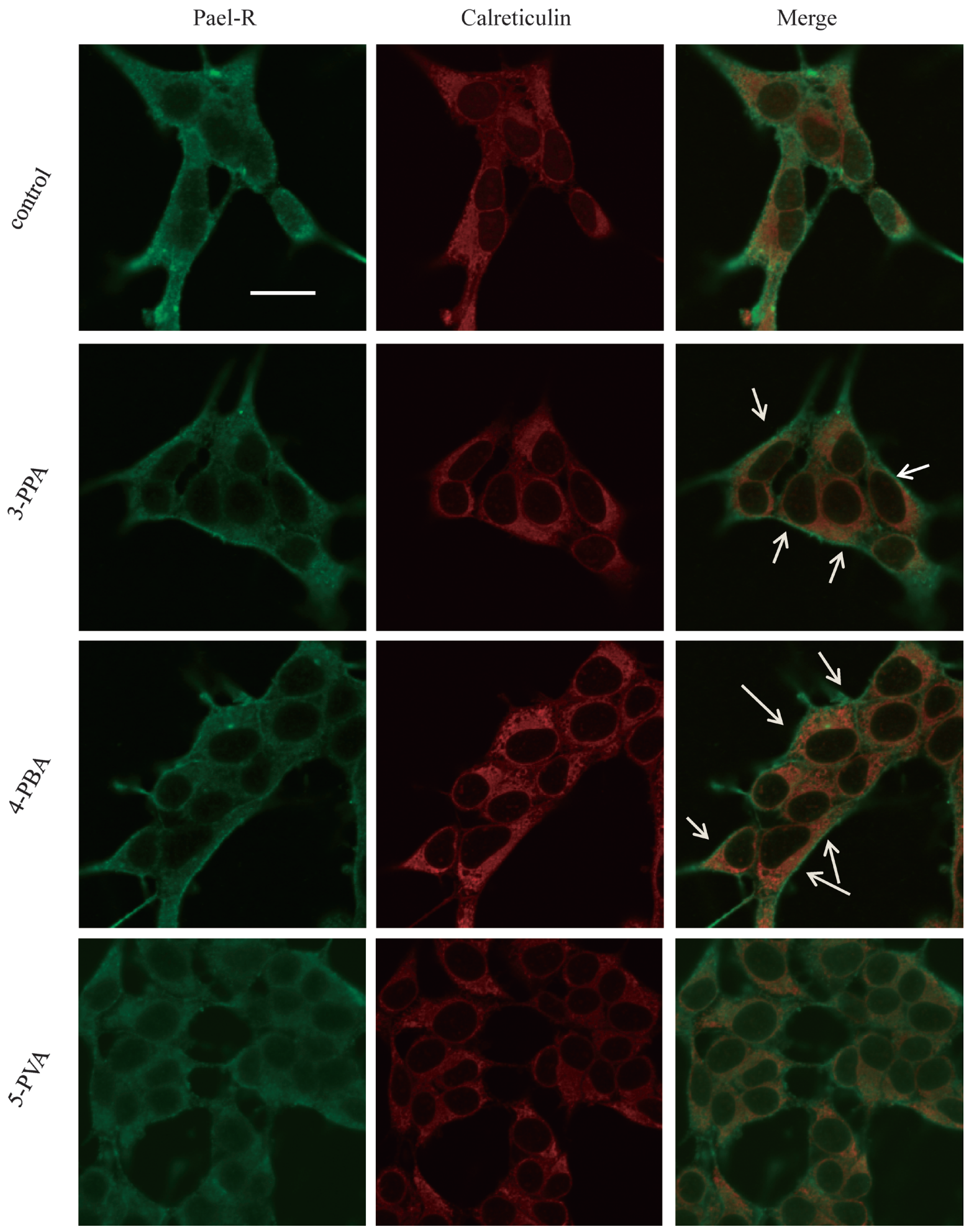

Fig. 5. Restoration of Pael-R Localization

SH-SH5Y cells stably expressing FLAG-tagged Pael-R were incubated with or without 3-PPA, 4-PBA, and 5-PVA for 48 $\mathrm{h}$ at a concentration of $3 \mathrm{~mm}$. The intracellular localization of Pael-R (green) and calreticulin (red) was visualized by immunofluorescence microscopy using anti-FLAG and anti-calreticulin antibodies, respectively. Properly localized Pael-R is indicated by arrowheads. Scale bar $=20 \mu \mathrm{m}$.

dency correlated well with that of the potency of these compounds on GRP94 and GRP78 expression.

We reported previously that 4-PBA protected against Pael$\mathrm{R}$-induced cell death, and that 4-PBA restored the normal localization of Pael-R. ${ }^{26}$ ) Overexpression of Pael-R induces cell death. In the present study, in order to compare the effects of terminal aromatic substituted fatty acids, we examined the effect of these compounds on Pael-R-induced cell death (Fig. 4). Both 3-PPA and 4-PBA effectively suppressed Pael-Rinduced cell death. In addition, 5-PVA and 6-PHA showed a tendency to suppress cell death. We hypothesized that 6-PHA and 5-PVA would be more effective than 4-PBA in suppress- 

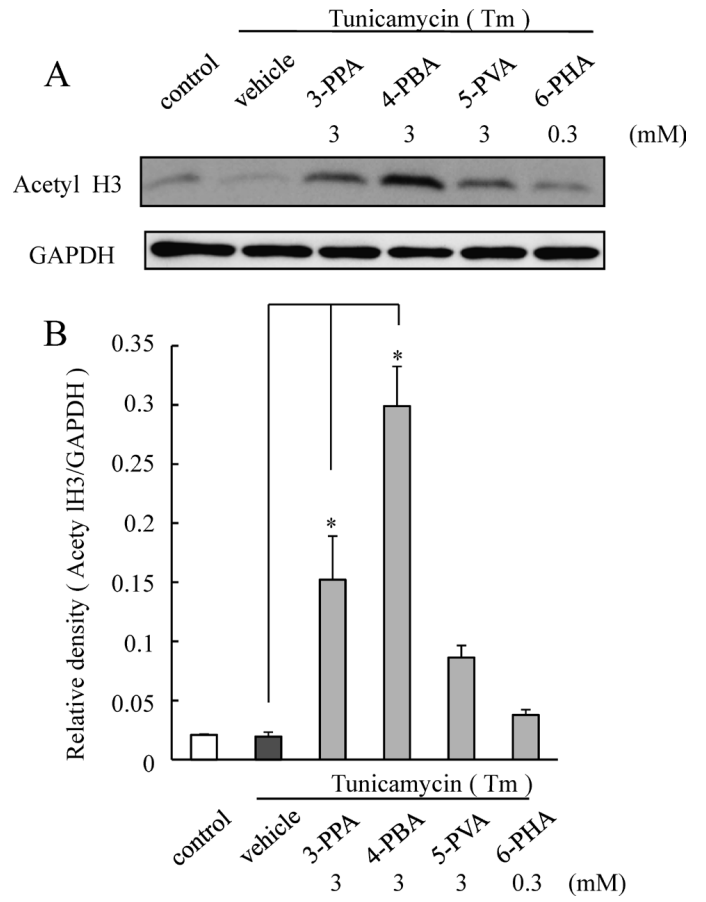

Fig. 6. Effects of the Test Compounds on ER Stress-Induced Acetylated Histone H3 Expression in Human Neuroblastoma SH-SY5Y Cells

(A) SH-SY5Y cells were treated with $100 \mathrm{ng} / \mathrm{mL} T_{\mathrm{m}}$ in the presence or absence of test compounds, and immunoblotting was performed using an anti-acetyl-histone H3 antibody. GAPDH served as an internal control in the immunoblotting analysis. The data presented are from a representative experiment of three independen experiments performed. (B) The levels of acetylated histone $\mathrm{H} 3$ were quantified by densitometric analysis and normalized to that of the corresponding GAPDH internal control $\left({ }^{*} p<0.05\right.$ : compared with vehicle control, Dunnett's test).

ing Pael-R-induced cell death as we observed that 6-PHA exhibited the most effective chemical chaperone activity (Fig. 1). Moreover, 6-PHA and 5-PVA were more effective than 4-PBA in suppressing ER stress-induced neuronal cell death (Fig. 2). Surprisingly, 6-PHA and 5-PVA did not suppress Pael-R-induced cell death. Thus, for the suppression of Pael-R-induced cell death, the suppression potency of these compounds did not show any tendency to be related to the number of carbons in the terminal aromatic substituted fatty acids. Moreover, we examined the effect of these compounds on the intracellular localization of overexpressed Pael-R protein. Pael-R protein migrates from the ER to the cytoplasmic membrane. Overexpressed Pael-R protein tends to accumulate in the ER. Both 3-PPA and 4-PBA reduced the accumulation of Pael-R protein due to overexpression and they transported Pael-R protein from the ER to the plasma membrane (Fig. 5). In accordance with this finding, 3-PPA and 4-PBA suppressed Pael-R-induced cell death.

A previous study reported that 4-PBA inhibits HDAC activity, ${ }^{10)}$ and, in the present study, we found that 3-PPA also possessed HDAC inhibitor activity, even though the inhibitory effect of 4-PBA was more potent than that of 3-PPA. However, the inhibitory effects of 5-PVA and 6-PHA were lower than that of 4-PBA and 3-PPA (Fig. 6). These differences in the potencies in inhibiting HDAC activity may affect their suppressive effects on Pael-R-induced neuronal cell death. That is, not only chemical chaperone activity but also HDAC inhibitor activity may be involved in cytoprotective effects against neuronal cell death. In fact, HDAC inhibitors have been reported to augment Sp1-dependent gene expression, and protect against oxidative stress-induced death. ${ }^{27)}$ Moreover, HDAC inhibitors have been suggested as therapeutic agents for neurodegenerative diseases such as multiple sclerosis. ${ }^{28)}$

4-PBA decreased the number of phosphorylated $\alpha$-synpositive neurons in human $\alpha$-syn A30P- and A53T-transgenic mice. ${ }^{19)}$ Moreover, 4-PBA increased the mRNA expression levels of the components of the ubiquitin-proteasome pathway and downregulated caspase-3 immunoreactivity in the striatum from the N171-82Q transgenic mouse model of Huntington's disease. ${ }^{29)}$

In conclusion, not only 4-PBA but also other terminal aromatic substituted fatty acids may be candidates for the treatment of neurodegenerative diseases.

Acknowledgments We thank Prof. Ryosuke Takahashi (Department of Neurology, Kyoto University Graduate School of Medicine, Kyoto, Japan) and his associates for generously donating the pcDNA3.1-Pael-R plasmid. This work was partly supported by a Sasakawa Scientific Research Grant from the Japan Science Society. In addition, this work was supported by Grants-in-Aid for Scientific Research (21590101, 21300142, 20659013, and 21590120) from the Ministry of Education, Culture, Sports, Science and Technology of Japan.

\section{REFERENCES}

1) Pepys MB, Herbert J, Hutchinson WL, Tennent GA, Lachmann HJ, Gallimore JR, Lovat LB, Bartfai T, Alanine A, Hertel C, Hoffmann T, Jakob-Roetne R, Norcross RD, Kemp JA, Yamamura K, Suzuki M, Taylor GW, Murray S, Thompson D, Purvis A, Kolstoe S, Wood SP, Hawkins PN. Targeted pharmacological depletion of serum amyloid $\mathrm{P}$ component for treatment of human amyloidosis. Nature, 417, 254-259 (2002).

2) Hammarström P, Wiseman RL, Powers ET, Kelly JW. Prevention of transthyretin amyloid disease by changing protein misfolding energetics. Science, 299, 713-716 (2003).

3) May BC, Fafarman AT, Hong SB, Rogers M, Deady LW, Prusiner $\mathrm{SB}$, Cohen FE. Potent inhibition of scrapie prion replication in cultured cells by bis-acridines. Proc. Natl. Acad. Sci. U.S.A., 100, 3416-3421 (2003).

4) Sánchez I, Mahlke C, Yuan J. Pivotal role of oligomerization in expanded polyglutamine neurodegenerative disorders. Nature, 421, 373-379 (2003).

5) Klucken J, Shin Y, Hyman BT, McLean PJ. A single amino acid substitution differentiates Hsp70-dependent effects on alpha-synuclein degradation and toxicity. Biochem. Biophys. Res. Commun., 325, 367-373 (2004).

6) Kitada T, Asakawa S, Hattori N, Matsumine H, Yamamura Y, Minoshima S, Yokochi M, Mizuno Y, Shimizu N. Mutations in the parkin gene cause autosomal recessive juvenile parkinsonism. $\mathrm{Na}$ ture, 392, 605-608 (1998).

7) Imai Y, Soda M, Takahashi R. Parkin suppresses unfolded protein stress-induced cell death through its E3 ubiquitin-protein ligase activity. J. Biol. Chem., 275, 35661-35664 (2000).

8) Imai Y, Soda M, Inoue H, Hattori N, Mizuno Y, Takahashi R. An unfolded putative transmembrane polypeptide, which can lead to endoplasmic reticulum stress, is a substrate of Parkin. Cell, 105, 891-902 (2001)

9) Yang Y, Nishimura I, Imai Y, Takahashi R, Lu B. Parkin suppresses dopaminergic neuron-selective neurotoxicity induced by Pael-R in Drosophila. Neuron, 37, 911-924 (2003).

10) Kubota K, Niinuma $Y$, Kaneko M, Okuma $Y$, Sugai M, Omura T, Uesugi M, Uehara T, Hosoi T, Nomura Y. Suppressive effects of 
4-phenylbutyrate on the aggregation of Pael receptors and endoplasmic reticulum stress. J. Neurochem., 97, 1259-1268 (2006).

11) Qi X, Hosoi T, Okuma Y, Kaneko M, Nomura Y. Sodium 4-phenylbutyrate protects against cerebral ischemic injury. Mol. Pharmacol., 66, 899-908 (2004)

12) Brusilow SW, Maestri NE. Urea cycle disorders: diagnosis, pathophysiology, and therapy. Adv. Pediatr., 43, 127-170 (1996).

13) Collins AF, Pearson HA, Giardina P, McDonagh KT, Brusilow SW, Dover GJ. Oral sodium phenylbutyrate therapy in homozygous beta thalassemia: a clinical trial. Blood, 85, 43-49 (1995).

14) Mercuri E, Bertini E, Messina S, Pelliccioni M, D’Amico A, Colitto F, Mirabella M, Tiziano FD, Vitali T, Angelozzi C, Kinali M, Main $\mathrm{M}$, Brahe C. Pilot trial of phenylbutyrate in spinal muscular atrophy. Neuromuscul. Disord., 14, 130-135 (2004).

15) Carducci MA, Gilbert J, Bowling MK, Noe D, Eisenberger MA, Sinibaldi V, Zabelina Y, Chen TL, Grochow LB, Donehower RC. A phase I clinical and pharmacological evaluation of sodium phenylbutyrate on an 120-h infusion schedule. Clin. Cancer Res., 7, $3047-3055$ (2001).

16) Ozcan U, Yilmaz E, Ozcan L, Furuhashi M, Vaillancourt E, Smith RO, Görgün CZ, Hotamisligil GS. Chemical chaperones reduce ER stress and restore glucose homeostasis in a mouse model of type 2 diabetes. Science, 313, 1137-1140 (2006).

17) Tveten K, Holla ØL, Ranheim T, Berge KE, Leren TP, Kulseth MA. 4-Phenylbutyrate restores the functionality of a misfolded mutant low-density lipoprotein receptor. FEBS J., 274, 1881-1893 (2007).

18) Inden M, Kitamura $Y$, Takeuchi H, Yanagida $T$, Takata K, Kobayashi Y, Taniguchi T, Yoshimoto K, Kaneko M, Okuma Y, Taira $\mathrm{T}$, Ariga H, Shimohama S. Neurodegeneration of mouse nigrostriatal dopaminergic system induced by repeated oral administration of rotenone is prevented by 4-phenylbutyrate, a chemical chaperone. $J$. Neurochem., 101, 1491-1504 (2007).

19) Ono K, Ikemoto M, Kawarabayashi $T$, Ikeda $M$, Nishinakagawa $T$, Hosokawa M, Shoji M, Takahashi M, Nakashima M. A chemical chaperone, sodium 4-phenylbutyric acid, attenuates the pathogenic potency in human alpha-synuclein A30P+A53T transgenic mice. Parkinsonism Relat. Disord., 15, 649-654 (2009).
20) Ricobaraza A, Cuadrado-Tejedor M, Pérez-Mediavilla A, Frechilla D, Del Río J, García-Osta A. Phenylbutyrate ameliorates cognitive deficit and reduces tau pathology in an Alzheimer's disease mouse model. Neuropsychopharmacology, 34, 1721-1732 (2009).

21) Huang G, Li ZY, Zhou JM. Conformational specificity of trigger factor for the folding intermediates of alpha-lactalbumin. Biochim. Biophys. Acta, 1480, 77-82 (2000).

22) Kuwajima K. The molten globule state as a clue for understanding the folding and cooperativity of globular-protein structure. Proteins, 6, 87-103 (1989).

23) Li J, Zhang S, Wang C. Only the reduced conformer of alphalactalbumin is inducible to aggregation by protein aggregates. $J$. Biochem. (Tokyo), 129, 821-826 (2001).

24) Wang XZ, Harding HP, Zhang Y, Jolicoeur EM, Kuroda M, Ron D. Cloning of mammalian Irel reveals diversity in the ER stress responses. EMBO J., 17, 5708-5717 (1998).

25) Iwawaki T, Hosoda A, Okuda T, Kamigori Y, Nomura-Furuwatari C, Kimata Y, Tsuru A, Kohno K. Translational control by the ER transmembrane kinase/ribonuclease IRE1 under ER stress. Nat. Cell Biol., 3, 158-164 (2001).

26) Rubenstein RC, Egan ME, Zeitlin PL. In vitro pharmacologic restoration of CFTR-mediated chloride transport with sodium 4-phenylbutyrate in cystic fibrosis epithelial cells containing delta F508CFTR. J. Clin. Invest., 100, 2457-2465 (1997).

27) Ryu H, Lee J, Olofsson BA, Mwidau A, Deodoglu A, Escudero M, Flemington E, Azizkhan-Clifford J, Ferrante RJ, Ratan RR. Histone deacetylase inhibitors prevent oxidative neuronal death independent of expanded polyglutamine repeats via an Sp1-dependent pathway. Proc. Natl. Acad. Sci. U.S.A., 100, 4281-4286 (2003).

28) Faraco G, Cavone L, Chiarugi A. The therapeutic potential of HDAC inhibitors in the treatment of multiple sclerosis. Mol. Med., 17, $442-447$ (2011).

29) Gardian G, Browne SE, Choi DK, Klivenyi P, Gregorio J, Kubilus JK, Ryu H, Langley B, Ratan RR, Ferrante RJ, Beal MF. Neuroprotective effects of phenylbutyrate in the N171-82Q transgenic mouse model of Huntington's disease. J. Biol. Chem., 280, 556-563 (2005). 